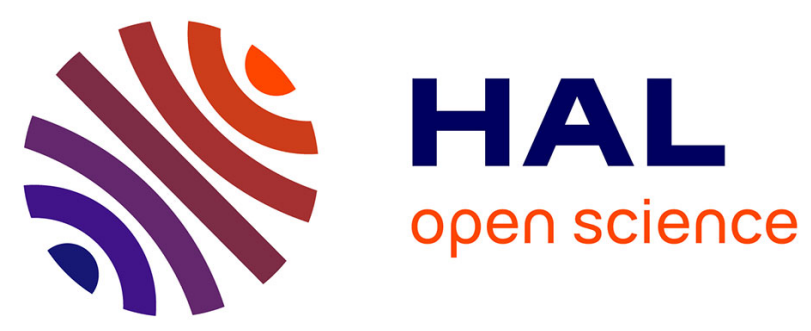

\title{
Gut Health in the era of the Human Gut Microbiota : from metaphor to biovalue
}

\author{
Vincent Baty, Bruno Mougin, Catherine Dekeuwer, Gérard Carret
}

\section{To cite this version:}

Vincent Baty, Bruno Mougin, Catherine Dekeuwer, Gérard Carret. Gut Health in the era of the Human Gut Microbiota: from metaphor to biovalue. Medicine, Health Care and Philosophy, 2014, 17 (4), pp.579-597. 10.1007/s11019-014-9552-2 . hal-01791760

\section{HAL Id: hal-01791760 https://univ-lyon3.hal.science/hal-01791760}

Submitted on 11 Oct 2020

HAL is a multi-disciplinary open access archive for the deposit and dissemination of scientific research documents, whether they are published or not. The documents may come from teaching and research institutions in France or abroad, or from public or private research centers.
L'archive ouverte pluridisciplinaire HAL, est destinée au dépôt et à la diffusion de documents scientifiques de niveau recherche, publiés ou non, émanant des établissements d'enseignement et de recherche français ou étrangers, des laboratoires publics ou privés. 
Vincent Baty • Bruno Mougin • Catherine Dekeuwer • Gérard Carret «Gut Health in the era of the Human Gut Microbiota: from metaphor to biovalue » Medicine Health Care and Philosophy · March 2014

\begin{abstract}
The human intestinal ecosystem, previously called the gut microflora is now known as the Human Gut Microbiota (HGM). Microbiome research has emphasized the potential role of this ecosystem in human homeostasis, offering unexpected opportunities in therapeutics, far beyond digestive diseases. It has also highlighted ethical, social and commercial concerns related to the gut microbiota. As diet factors are accepted to be the major regulator of the gut microbiota, the modulation of its composition, either by antibiotics or by food intake, should be regarded as a fascinating tool for improving the human health. Scientists, the food industry, consumers and policymakers alike are involved in this new field of nutrition. Defining how knowledge about the HGM is being translated into public perception has never been addressed before. This raises the question of metaphors associated with the HGM, and how they could be used to improve public understanding, and to influence individual decision-making on healthcare policy. This article suggests that a meeting of stakeholders from the social sciences, basic research and the food industry, taking an epistemological approach to the HGM, is needed to foster close, innovative partnerships that will help shape public perception and enable novel behavioural interventions that would benefit public health.
\end{abstract}

Keywords Human Gut Microbiota Metaphors Biovalue Gut Health Nutrition Antibiotics Bacterial resistance

\title{
Introduction
}

The advent of microbiological genomics gave rise to numerous studies highlighting the fundamental role of microbes located in the human gut in host homeostasis. Historically called the gut microflora [Tapez ici] 
and today known as the Human Gut Microbiota (HGM) the close relationships between these bacteria, our immune system and many metabolic functions that control the stability and efficiency of the gut barrier, are now established. Although our understanding of the HGM regulation is still developing, an increasing body of literature, mostly in top medical journals, is now available, reporting on the key role of this microscopic ecosystem in human health and diseases (Kau et al. 2012; Tremaroli and Ba"ckhed 2012).

The HGM is sometimes referred to as "our second stock of genes" (Klingler 2009) and, like the Human Genome Project, the subject has rapidly evolved. Today it is no longer a matter of merely understanding HGM regulation, but of implementing techniques and methods that would enable HGM modulation as a way, at a minimum, to improve Gut Health and avoid disease. The term Gut Health emerged in the early 2000s in the scientific literature (Cummings 2004) as well as in food industry advertising but remains hard to define. An exhaustive review of the literature focusing on Gut Health as an objective in medical care, clearly stated the limits and difficulties of defining and assessing what is meant by that term (Bischoff 2011). Five major criteria were isolated, including (1) an effective digestion and absorption of food, (2) the absence of gastro-intestinal illness, (3) a normal and stable intestinal microbiota, (4) an effective immune system, and (5) the state of wellbeing. These criteria demonstrated the importance of subjective parameters (Bischoff 2011).

In 1946, the preamble of the Constitution of the World Health Organization defined Health as " a state of complete physical, mental and social well-being and not merely the absence of disease or infirmity", (Grad 2002: 984). Today, very advanced or basic research that might improve global health and its management is associated an added value which can be interpreted either as a subjective assessment, in terms of improving individual well-being, or in the context of bioeconomy, as an economic advantage that might impact healthcare costs.

In biology, the term biovalue was initially used in the field of stem cells and tissue culture. It has since shifted to use in the context of biobanking (Waldby 2002; Mitchell 2010). The concept of biovalue, " "refers to the yield of vitality produced by the biotechnical reformulation of living processes" (Waldby 2002: 310). The genomics revolution demonstrates that Waldby's analysis might be extrapolated from stem cell culture " to other types of tissue resources [...] in order to develop a wide-ranging, empirically based understanding of biovalue and tissue economies"' (Kent et al. 2006: 2). Considering the key role of nutrition guidelines, especially in the prevention and treatment of noncommunicable diseases, the notion of biovalue applied to the field of the HGM suggests a kind of profit, either directly, as a source of income, or indirectly, as a means to prevent disease and thus reduce healthcare costs. Nevertheless, 
the concept of the HGM stands at the intersection between public health policies, with their compulsory economic constraints, and the public's nutritional behaviours and their subjective view of Gut Health. Thus, biovalue remains hard to define as it could mean economic value, as well as the value of individual wellbeing.

Although we agree that ethical and social concerns have previously been discussed in the field of genomics as it applies to the HGM (Slashinski et al. 2012), far less conclusions have been published regarding the individual perception of that concept, including the mental and symbolic representations associated with the bacterial world, the gut and its related functions. Nor have publications addressed the food choices that consumers could accept to change in order to improve their personal Gut Health and overall wellbeing. In fact, most of the available literature related to the HGM has focused on human pathology. Therefore, the actual point of view of healthy consumers on the relationship between the HGM and Gut Health has never really been addressed before and remains hypothetical. This raises the challenge of how to engage the public in nutrition programmes based on HGM modulation, as a tool for preventing chronic and noncommunicable diseases. There is a chance that each individual, when confronted with the concept of the HGM and its expected modulation through dietary programmes or antibiotic treatment, for instance, might likely take a stand based on cultural and personal criteria, regardless of scientific communication.

We therefore suggest that the first step to addressing this challenge should be to analyse the meaning of the HGM and Gut Health for lay consumers, in order to better differentiate the notions of understanding, knowledge and perception in this field. We argue that this could play a key role in improving public health policies in the field of nutrition. This article will also focus on the role of metaphors related to the HGM on a performative and discursive level. Hence, we uphold that exploring consumer perceptions of the HGM should help improve the dialogue between Society and scientific experts, whatever their profession (biologists, physicians, members of the food industry, public health agencies, ...). Thus, we arrive at the conclusion that now is the time for a deeper analysis of the public's perception of the HGM as it might directly influence the efficacy of communication on Gut Health. Such an analysis would also help to better address the objectives of the food industry and, subsequently, the related economic and societal consequences in terms of biovalue.

The first part of the article discusses how the HGM has emerged as a potential new paradigm and introduces, with more tangible results, its current place in human health and disease. The second part presents the conceptual framework of the article, grounded on the global concept of metaphor, specifically in the field of biology and Gut Health, and focuses on its key role in dialogue among human

[Tapez ici] 
communities. This section contains a debate on the role of metaphors related to the HGM as a way to optimise the communication between scientists, the food industry and the public. We attempt to decipher what an ideal metaphor could be for the field of HGM, then must admit that the frontier between metaphors and mental representation can be hard to define. The third part scrutinizes the methodology of the study, focused on an unusual approach that could be defined as a virtual epistemological meeting, through the analysis of the available literature. This process is a first step towards making the various nutrition programme stakeholders aware of the consumer's symbolic representation of Gut Health in the era of HGM. Thus, the next section addresses the key role of uncovered metaphors in the field of HGM, which to the best of our knowledge, has never been assessed before. Our analysis aims at showing that communication on the HGM might be characterised by an increasingly anthropomorphic perception, which cannot be regarded as a mere semantic evolution. Consequently, the fifth section attempts to disclose how deciphering metaphors related to the HGM could initiate novel insights on specific issues, not only dedicated to major and current medical concerns, but also influenced by social and philosophical scrutiny. The conclusion, presented in the form of perspectives, finally suggests that, in light of what could be accepted as the HGM paradigm, a framework for novel partnerships could be built to develop public health policies in the field of nutrition, grounded in effective public engagement and well-adapted dialogue.

\section{Historical analysis}

The Human Gut Microbiota comes of age

We would like to introduce our idea by questioning the current weight of the HGM in the field of microbiology. Indeed, before the advent of the "omic"' methods, evidence showed that the microbial world was neglected in philosophical and biological discourse (O' Malley 2013). Bacteria have usually been considered as a potential threat for humans since the early research performed by Pasteur at the end of the nineteenth century. As a result, antibiotics were chosen as the efficient and definitive riposte until the end of the twentieth century and the emergence of bacterial resistance, which was usually driven by the overuse of these molecules. However, beyond the issues of antibiotic efficacy and bacterial resistance, numerous studies have also reported that antibiotics impair microbial ecosystems, sometimes with a direct and negative clinical effect, as demonstrated by antibiotic-related colitis, which is emblematic in this field (Brandt 2013). Hence, the idea has progressively caught on that some bacterial communities might be of value for human homeostasis. Today, bacterial species no longer are viewed 
just as negative partners in the human health arena. Taking a step further, since the human's cells and genes are heavily outnumbered by those of their resident bacteria, and considering two opposite timescales (the potential impact of the HGM in human homeostasis as the future and the previous coevolution of humans and micro-organisms as the past), some have even proposed, as an extreme and provocative admonition, that every human-being should be considered "as a bacteria" (Triggle 2012). A much more balanced attitude would probably be to come to terms with our bodies " as vessels floating through a microbial web of life and providing a hospitable environment for the species that inhabit us" (Zwart 2010: 48).

The shift in perception about the bacterial world has especially concerned the intestinal ecosystem, previously called the gut microflora, and now known as the HGM. Although clinicians learned long ago of the potential role of these microorganisms in digestive diseases, discovered a century ago by Metchnikoff (Podolsky 2012), an accurate understanding of this ecosystem in human homeostasis was lacking. As a result, the benefits of nutritional interventions were of limited interest until recently.

Things have dramatically changed in this field with the development of microbiome research (nucleic acid-based technologies, culture-independent molecular testing, proteomic and metabolomic studies, metagenomics). What are commonly known as the "omic" techniques have revealed numerous novel bacteria species and new cell functions. Above all, and especially in the field of HGM, they have shown the extent of microbial abilities to cooperate and communicate, provided the microbes are regarded as communities. The "omic"' methods have also led to new insight into evolution and microbial ontology (O'Malley and Dupre' 2007; McDonald et al. 2013). As an additional factor in the complexity of this ecosystem, exploring this issue in the light of evolutionary ecology, one should also consider that by studying the stabilized microbial entities of an animal gut using metagenomic methods at particular times, one runs the risk of underestimating the role of time scales in the stabilization of microorganisms (Bapteste and Dupre' 2013). Furthermore, on the basis of a multilevel "omic" approach and although our understanding of the interactions within HGM communities is still in progress, the available data demonstrate that "metacommunity analysis appears to be an inevitable development of single community studies in the microbial world" (Zarraonaindia et al. 2013). As we can see, the use of "omic" techniques and the data related to the potential role of HGM modulation have forced both biology and philosophy to reconsider "the scope and the testing”' of microbiology (O'Malley 2013). Consequently, it is not surprising that the increasing results of basic research focusing on the HGM have emphasized the importance of this ecosystem in human homeostasis. Research shows unexpected opportunities for the management of a variety of clinical conditions, far beyond the field of digestive 
diseases, through planned modulations of the HGM's composition. In fact, an increasing number of recent and on-going studies report on the role of the HGM, in allergy and in various metabolic disorders involved in noncommunicable diseases, focusing on clinical conditions related to obesity, cardiovascular pathologies, and even mental disorders.

At the same time, the advances in genomics and information technologies, and the ethical issues they raise, have pushed back the frontiers of what had been accepted as humankind's ontological foundations. These technologies broaden the human sphere of activity in fields that, until recently, fell in the realm of necessity, according to biophysical laws, or in the realm of fatality, according to a metaphysical perspective. In fact, the technologies have changed our perception of four key aspects of human life (1) birth, with medically assisted procreation methods, (2) health, with its evolving definition, (3) aging, considered as a natural event or as a disease and finally (4) death, with resuscitation techniques in intensive care units.

Genomics have also altered our understanding of identity as we are no longer an individuum, but rather inhabited by a myriad of organisms who allow us to function as a whole. This obviously has serious consequences in terms of property, justice and ethics as reported even in the lay press (Zimmer, 2011). Today, our internal microbial environment could be looked at as a novel organ whose modulation, through diet or through therapeutics such as probiotics, antibiotics or faecal transplantation, raises ethical, economic and biopolitical concerns.

This has emerged in the field of HGM in discussions about the implications of biobanking (Hawkins and O'Doherty 2011). It has also brought attention to the challenge of commercialising human microbiome research, as recently reported by Slashinski and colleagues (Slashinski et al. 2012), who compared the concept of biovalue to the public perception in this field, drawing upon the comments of researchers involved in the Human Microbiome Project. As we postulated in the introduction, this study stated that the definition of biovalue mightbeconsidereddifferentlydependingonifitisappliedto the scientific community or to the lay public. These authors concluded with "the need to find a balance between the marketplace, scientific research, and the public's health', (Slashinski 2012: 28). In addition, the need to better understand how diet and "lifestyles influence the assembly of gut microbial communities" (Kau et al. 2012: 327) has been raised, while other authors have wondered how to find the best way of moving from " a product-oriented industry to a customer-oriented one" (Asch and Volpp 2012: 889). Thus, beyond the meaning of the rediscovery of an "interior world" from a philosophical standpoint, the available literature and on-going studies devoted to the relationships between the HGM, nutrition, "Public Health"' and 'Global Health', naturally lead the scientific community as a whole to 
concentrate onthisissue. In this context, particular attention is given to the areas of Gut Health and bacterial biovalue, both with their economic and subjective connotations. The "omic" techniques have opened a new dimension in microbiology, leading philosophers and biologists alike to pay close attention to this field (O’Malley 2013).

The current place of the HGM in the fields of nutrition and health

It is time now to explore the real influence that modulating the HGM could have on human health. Infectious diseases were a major concern in human health until the first part of the twentieth century, when the use and the efficacy of antibiotics left a strong mark. Unfortunately, due to the resilience of bacteria, evidence rapidly showed (1) that antibiotics would never completely control bacterial infectious diseases, and (2) that humankind would have to live and deal with bacteria and look upon this microbial world in a new light. Conversely, the second part of the twentieth century showed the increasing burden of noncommunicable diseases such as diabetes, metabolic disorders, allergies, mental disorders, immune-mediated diseases and cancers. This increase was not only the consequence of progress in diagnostic methods but also was the result of human behaviours adapted to changing environmental and social conditions. It is now accepted that "Global Health", which can be defined as "public health for the world" (Fineberg and Hunter 2013) cannot be improved without a better understanding of the risk factors in personal behaviours, such as poor diet (Fineberg and Hunter 2013).

The role of the HGM in human health was first demonstrated in inflammatory bowel diseases. Numerous studies have since reported its potential implication in diverse clinical conditions, such as those related to obesity and allergy, or in physiological regulations, especially through the brain-gut axis and the immune system. Reviews in top journals have reported on the increasingly broad scope of the HGM's influence in the field of human diseases (Kau et al. 2012; Petrof et al. 2013; Foster 2013). In addition, basic research has revealed that diet factors are the major regulator of the HGM (Moschen et al. 2012), and recent data have clearly demonstrated that a sustained modulation of the HGM, following either unusual food intake or the prescription of antibiotics, should lead to a substantial and prolonged shift in its composition. Thus, there is some evidence that the concept of HGM lies at the interface of biological and sociological issues, where individual behaviour and public health goals intersect.

More globally, this raises the question of what could be the evolution and future of human beings. Studies on probiotics (Brinich et al. 2013) and functional foods (Eden 2011) suggest that the role of the public's knowledge and information in these fields should not be overlooked. One must consider (1) the increasing weight of the HGM in health issues, (2) the close relationship between diet and the HGM, [Tapez ici] 
and (3) that consumers are ultimately the ones most concerned with choices related to their dietary habits. As a result, each consumer could be regarded as a kind of "health expert" with regards to nutrition, industrial products and healthcare policies. Taking this into consideration, we must analyse what would be desirable, realistic or possible for the consumers role to be, at individual and global health levels.

Metaphors as a conceptual framework

As reported by van der Weele, metaphors "govern, shape and frame" our lives "on the level of language, but also on the level of perception, conception, and affection'" (van de Weele 2008: 2). Indeed, the fields addressed by metaphors are diverse and occur not only in the public realm, but also in science. For instance, in medicine, it is not surprising that radiology is a favourite specialty for the use of metaphors, as it enables the lay person, to discover the body in deep and intriguing ways (Baker and Partyka 2012). Conversely, although digestive endoscopies should be of comparable interest, less has been reported on the use of metaphors in this field. It seems of value to study how the concept of the HGM might influence communication on advances in the field of Gut Health. Although the scientific and medical literature devoted to modulating the HGM, available in journals specialising in basic research and evidence-based medicine (Hawkins and O'Doherty 2011), has mentioned legal and ethical concerns, the public's perception of the HGM has hardly ever been addressed beyond its role in human pathology (Zipursky et al. 2012; Kahn et al. 2012). Yet, one can imagine that understanding the consumer's knowledge and perception of the HGM might help to better analyse (1) how this would impact nutritional interventions in public health, and (2) how the social sciences could help basic research in this field. For instance, behavioural intervention has been shown to be the most effective therapy in the treatment of obesity (Levy et al. 2007), and an analysis of how patients view probiotics, particularly in the context of online communications, showed that their expectations were, on the whole, highly unrealistic, fed by biased information (Brinich et al. 2013). Experts' metaphors in the scientific discourse are usually considered to be tools for improving the public's understanding. Nevertheless, there is currently no answer to the question of what determines the consumer's attitude towards food choice in the era of the HGM. Facing these issues prompts us to estimate how close the public perception of the HGM is to the experts' metaphors, since this might influence the individual determinants of consumers' attitudes and practitioner's advice regarding food choice or the use of antibiotics and probiotics (Mercer et al. 2012).

It has been stressed that "scientists and policy makers might use certain culturally available and historically entrenched metaphors to frame scientific discoveries or policies, without initially reflecting 
on the wider implication their choices may have"' (Zinken et al. 2008: 366). These metaphors should be considered as primary conceptual metaphors and this assumption suggests that the effectiveness of metaphors "'as a pervasive process of meaning creation", (Zinken et al. 2008: 364) might depend on how closely they correlate with the public's background and personal history. How far could this be assumed in the field of HGM?

As Nerlich pointed out, "According to the cognitive linguistic view of metaphor, metaphors help us understand an abstract or inherently unstructured subject matter in terms of a more concrete, more highly structured subject matter" (Nerlich and Hellsten 2009: 24). Considering the basis of primary conceptual metaphors, they are supposed to fill the gap between two conceptual domains: the source and the target. But the real world seems much more complex since the source and the target can be considered in varying ways. Indeed, metaphors also occur in scientific research as bridges to other levels, since they help bring together the language of different groups (scientists, consumers, journalists...). Hence, metaphors are an obvious tool for sharing knowledge. In this assumption, metaphors are, on the whole, oriented from the source "who knows" towards the target "who needs or wants to know". Thus, most of the time and specifically in the field of microbiomics, metaphors could definitely be accepted as the expression of the scientist's point of view (Nerlich and Hellsten 2009). The question of whether or not these metaphors are relevant seems essential, but one must keep in mind that the public perception itself of the HGM is liable to interfere in the form of unofficial beliefs, grounded on symbols and mental representation that resist the power of institutionalised messages. Hence, although it could seem practical, at first glance, to define the term "mental representation" as the spontaneous perception of the HGM by consumers, and the term "metaphor" as the way for scientists and public health experts to translate current knowledge and scientific advances, this way of thinking would suggest that the idea of communication between experts and the public is seen as moving only in one direction, while the idea of a meeting implies a dialogue. We must also consider, as a significant parameter, the historical weight of the public imagery related to the concept of Gut Health. Thus, if we consider that deciphering the public perception of the HGM might help to assess the societal point of view, we must admit that the public's spontaneous mental representations and experts' metaphors are equal in terms of informational value. We have therefore chosen to only use the term metaphor in this article, whether we are referring to public's or experts' perceptions.

Numerous studies have reported on metaphors related to the myth of digestion and to the cultural meaning of nutrition and food intake, but none, to the best of our knowledge, have specifically focused on the HGM. We herein understand myth as "a carrier of both constructive and destructive norms and 
values" (Svalastog 2010: 481). Bachelard wrote, in particular, about the relationship between the myth of digestion and alchemy, and the pivotal role of stools and the anal phase in the field of psychological development (Bachelard 1967). His reflection compared the psychic experiences of pleasure in childhood with psychoanalysis that discloses an ambiguous acceptance of the metamorphosis of food into excrement (a magic chemistry leading to a kind of purified product versus the ugly, disgusting and worthless). He concluded that for what he called the "pre-scientific minds", digestion could only be considered under the "reign of values" (Bachelard 1967: 205). For instance, it is noteworthy that GOLD, the acronym of the Genome Online Database "can be seen as spates of informational excrement (spat out by sequencing machines with superbly productive intestines) that at the same time represent something of significant value, something 'pure",' (Zwart 2010: 41). The metaphor of alchemy and its correlates in terms of value, suggested by excrement being turned into GOLD and purity, cannot be better expressed. The question of how a metaphor is formed leads one to consider whether human thinking arises from words or from images. This is exactly the purpose of this article: to bring to light the fact that the matter has never been addressed before in the field of HGM, in stark contrast with the wide broadcasting of metaphors initiated by scientists and professional circles in other fields, such as those related to the Human Genome

Project.

Today, there is evidence that genomic technologies enable a new understanding and reveal unexpected data in fundamental sciences related to the HGM, and to its attendant implications in nutrition and Global Health. While it remains to be proven, the imagination of each individual and consumer is constantly searching for the best translational method to feed his or her knowledge and understanding of scientific discourse and information. Greenhalgh and Wieringa recently estimated the value of the "knowledge translation" metaphor in science, and they concluded upon the "complex links between power and knowledge", (Greenhalgh and Wieringa 2011: 501). Hence, if we accept consumers as health experts in the field of nutrition, the issue of the HGM questions the public's perceptions of this field and the available ways to acquire, understand and use information. As a result, studying the concept of the HGM can provide a fascinating opportunity to examine, which one among the following notions of public knowledge, understanding and perception, could be the most relevant in this field and assist the individual decision-making involved in determining healthcare policies. This implies reflecting upon: (1) how biologists, physicians, food industries and policy makers communicate through social media; (2) how we cope individually and collectively with new technologies (we herein use the term technology in the broad sense proposed by Mordini, as a "social practice that embodies 
the capacity of societies to transform themselves by creating and manipulating not only physical objects, but also symbols and cultural forms" (Mordini 2007: 544); (3) the influence these new technologies have compared with scientific information and advertising; and (4) how consumers finally picture their gut microbiota and its functions.

We have already suggested that metaphors should not be in conflict, whether they originate from professional experts or from the public. The more they complete each other, the more effective the knowledge translation. Hence, as an attempt to conclude this section, we put forth that there are actually no "bad" metaphors although sometimes they may appear to be more or less suitable. The point is to strengthen the relationship between the metaphor and the consumer's beliefs. In the field of HGM, we speculate that a good metaphor should integrate the cultural background of the given public. The function of HGM metaphors resulting from experts' points of view, should not be reduced to a mere translation of scientific truth but rather used to help consumers accept novel insights in the field of Gut Health, which fit with how they picture their own internal microbial symbiont. As a result, metaphors used as a tool for knowledge translation can clearly be useful, but most of the time they are not sufficient. The global public understanding depends on the ability of each individual to separate his or her imagination from scientific messages.

The purpose of this article is to evaluate the similarity of metaphors related to the HGM with societal expectations, as we presume that heterogeneous metaphors feed off each other to achieve a balance, provided communication is updated. This suggests, as postulated by Nerlich, that the analysis of a metaphor depends on time scales (Nerlich and Hellsten 2009). For instance, the shift in language observed in the field of genomics applied to HGM research since 2003 could mean that a new paradigm is arising, whereas before that, "continuity in metaphor use was more prominent than discontinuity" (Nerlich and Hellsten 2004). We conclude that an ideal metaphor for the HGM might not exist. We also conclude that there is a need to routinely evaluate metaphors related to the HGM in order to better adapt the available data mined from basic research to conscious and unconscious public expectations. This reflection should be linked with the notion of "discourse metaphor" defined by Zinken as " a relatively stable metaphorical projection that functions as a key framing device within a particular discourse over a certain period of time"' (Zinken et al. 2008: 364). According to this approach, discourse metaphors differ from primary conceptual metaphors by three characteristics: they "employ cultural knowledge", they "evolve in historical time"' and they "occur across languages"' (Zinken et al. 2008: 365-373). We definitely agree with this point of view for the field of the HGM.

[Tapez ici] 
Methodology

The advent of the "omics" techniques has increased the role of the HGM in human health. Indeed, the available literature reporting on the relationships between the HGM and human health forces us to view this concept as a novel paradigm rather than a fashionable subject. As reported, the issues related to the HGM refer to Health in terms of wellbeing and lifestyles, whose definitions remain subjective, mainly based on cultural and individual criteria. In other words, the close interactions between personal behaviours and the health of populations cannot be ignored (Ezzati and Riboli 2013; Atun et al. 2012). Hence, beyond the ethical and legal questions, which are obviously of major importance, the concept of the HGM also leads the scientific communities in basic research and the foodindustry to explore the kind of relationship they can build with the social sciences. This would serve to advance their understanding of the power of mental images as a tool to guide individual behaviours in the field of nutrition. Consequently, beyond the amazing importance of the HGM in pathological fields, as reported in the first section of the article, the original idea of the work presented here was supported by a philosophical insight and the analysis of the broad, heterogeneous meaning of the HGM for human beings. For example, its meaning in terms of identity but also in terms of potential behavioural changes as far as therapeutic implications are concerned. Thus, it seemed that a systematic analysis of the available data, whatever its origin or orientation, might be the most suitable way to approach this new paradigm.

This reflection arose from an unusual partnership between the University of Philosophy of Lyon and a consortium named BIOASTER, whose ultimate goals are to help the food-industry adapt its communication to societal expectations. BIOASTER is co-funded by the French government and private partners, and is the only healthrelated Technological Research Institute in France dedicated to infectious diseases and microbiology. This consortium brings together Lyonbiopole, Institut Pasteur, three industrial companies (Sanofi, Institut Me'rieux, Danone Research), three academic research centres (CNRS, INSERM, CEA) and forty small and medium-sized businesses. BIOASTER is a foundation for scientific cooperation and technological know-how and innovation. Moreover, beyond its industrial goals, BIOASTER aspires to a translational and collaborative organisation taking into account basic research, new technologies as well as societal and ethical concerns. Thus, the University of Philosophy of Lyon and BIOASTER have decided to undertake an innovative and unusual project: to explore the meaning of the HGM in terms of symbols and images, among different human communities. Both partners hypothesise that using social sciences to look at the HGM will help physicians, biologists and the food industry (1) to better understand what this concept represents for citizens and consumers (2) to 
consider how dietary guidelines could evolve in practical ways to achieve new public enlightenment and (3) to help BIOASTER achieve its goals with respect to addressing public health issues, consumer expectations and biovalue.

We have already noticed that pooling new methods in informatics with genomics makes it possible to analyse massive amounts of genomic data from a great number of specimens, in order to increase the knowledge of human diseases and thereby improve the efficacy of novel therapeutics (Hudson 2011). Looking at the field of the HGM and on the best way "to consider both how genes are perceived in the real world and what is actually known about their function" (Clayton 2003: 563), or "to enlarge and foster public engagement' (Zwart 2009: 542), we suggest that an epistemological approach can be initiated to uncover the psychological determinants of individual behaviours in the field of nutrition, which might be influenced by the metaphors associated with the HGM. With this in mind, we would especially like to highlight (1) how HGM metaphors can be considered as a way to simplify the translation of healthcare issues related to nutrition, and (2) the impact of individual mental representations of the HGM and related metaphors on food choice.

Yet beforehand, we must clarify the term "epistemological meeting" that we have coined for the purpose of this article. Although it differs from the constructivist or positivist approaches, and according to usual sources, epistemology can be defined as "the theory of knowledge, especially with regard to its methods, validity, and scope, and the distinction between justified belief and opinion" (Online Oxford Dictionaries). In addition, epistemology studies how to uncover the meaning of Science by bringing to light relationships between concepts that appear unfamiliar. Concerning the field of the HGM, the symbiosis between the host and the HGM today appears to be very close, but the public perception of the HGM, despite experts' communication, might still be rooted in metaphors that would probably benefit from a deeper epistemological analysis.

This article presents, as a first step, a partnership with a virtual dimension. The concept of stakeholder epistemological meeting must therefore be considered as a kind of metaphor. Our purpose was first to analyse the public perception of Gut Health in the era of HGM and then to correlate it to the professional experts' discourse. The purpose of this study is to analyse HGM metaphors among lay audiences and among scientists through mutual learning, dialogue and exchange. This first approach remains theoretical but aims, as a second step of the partnership, at building more traditional stakeholder meetings on HGM perceptions and applications. We chose the term "epistemological meeting”' (which to the best of our knowledge has never been used before) as a convenient and suitable term to express a specific way of looking at the field of Gut Health in the era of the HGM. It matters not only to the 
communities of scientists, physicians or members of the food industry who are obviously directly affected by this field, but also to the publics' point of view, as we consider that the purpose of such a meeting is not to allow science and industry to feed their metaphors to audiences who are wrongly suspected of being uninformed (since they must obviously have their ideas and metaphors about Gut Health). The objective of this epistemological meeting must be to uncover the metaphors evolving inside and outside scientific discourse. We would also like to draw attention to the limits of designing a formal stakeholder workshop for constructive technology assessments, which would result only in hypothetical evaluations and health experts' theories. We postulate that the professional experts' points of view could be biased, unless a reflection specifically focused on the public itself has taken place. Therefore, we suggest that an initial epistemological meeting dedicated to this could help to avoid, or at least to limit, the risk of misunderstanding between Society as a whole and professional scientific circles, as was the case for the Human Genome Project (Nerlich and Clarke 2002). The role of social sciences in emerging infectious diseases has recently been reported (Janes et al. 2012). Couldn't we have a similar debate in the field of HGM? We suggest that the time has come to explore the concept of HGM in greater depth since it takes place at the intersection of medicine, Society, healthcare policies, ethics, evolution and food-industry research. The field of HGM and its diet and health implications offer a unique opportunity for creating a new form of dialogue on healthcare issues between the social sciences, biologists, physicians, consumers, the food industry and policy-makers, focused on both the health decisions of individuals and populationbased programmes.

At first glance, a philosophical approach to the HGM could be regarded as rather academic with no practical application in the era of evidence-based medicine. But isn't that a bit simplistic? To what extent could metaphors and symbols related to the HGM be connected to medical and healthcare models? The question that is now raised is how consumers and scientists could improve communication on this field to correlate advances in science with Society's expectations. This implies evaluating (1) how Society is prepared to absorb these advances and how to implement nutrition programmes through changes in human behaviour, and (2) if scientists are well aware of public beliefs related to Gut Health. These considerations would definitely help to address two major issues: the first one, which is rather unexpected in the era of autonomy and personalised medicine in western countries, would be to admit, in practical terms, the actual place of the consumer in the area of diet and nutrition programmes; the second one questions how to better acknowledge the need for assistance from the social sciences in fields that are traditionally claimed by fundamental and/or industrial research. Furthermore, since transparency should characterise healthcare programmes, closely linking "soft" and fundamental 
sciences would also help to define what an ideal partnership could be between private and public sectors, (Hawkes and Buse 2011). The need is now great (1) to better define and measure Gut Health (Bischoff 2011) through dedicated studies (2) to elaborate truly innovative and efficient financing mechanisms in the field of nutrition (Atun et al. 2012), and (3) to build a bridge across disciplines in order to avoid "confusion within the public's mind relating to conflicting nutrition messages"' (McMahon et al. 2010: 285).

This epistemological work is in progress, but the very first results show that studying the HGM raises the need for a special dialogue between "soft" and "hard" sciences in order to combine health, wellbeing and commercial returns. This experience demonstrates that bringing together these two disciplines is a real challenge since, obviously, neither has a spontaneous propensity for the other (Mouton 2010). In fact, we consider that there is great need to analyse more deeply the public perception of the concept of the HGM and its attendant modulations before going further, either to make recommendations for the organisation of a future meeting or to clarify the framework of sociological studies on the subject. Consequently, the research has been conducted as a discourse analysis of the HGM metaphors in the available literature, whether they come from international scientific publications, discovered through a Medline search, or from the analysis of French print media.

Metaphors uncovered from the HGM concept - the anthropomorphic twist

Evidently, the concept of HGM involves mental representation and related symbolic language. Whereas in early modern times, the human body, notably the intestines, were opened up for the first time by pioneers, the gut microbiota was completely overlooked and left out of the picture for years, disregarded and actively removed as pure waste or as something not belonging to the body as such. Decades ago, movies and science joined forces to better portray what our body could look like on the inside. Famous Hollywood films such as Fantastic Voyage, by R. Fleisher in 1966, can be seen as an emblematic portrayal of the imaginary (Goffette 2012). The premise of this fiction was clearly that a better understanding of microscopic means of communication could help cure a body impaired by a cerebral attack so that it could communicate again with other humans. In fact, this movie was more interested in the means of communication within a deep, mysterious environment, than the discovery of a specific host-associated community.

The concept of HGM gives us new insight as it forms a microbial entity with its own rules and discloses new ways of communication through the immune cells of the host and the bacterial species. The concept of HGM is also a typical example of a specific human ability that could be considered our [Tapez ici] 
miniaturising imagination. Hence, considering the limits of the assumptions we have made about the definitions of "mental representation" and "metaphor', and from the standpoint of Bachelard, who postulated that the better we can miniaturise the world, the more we can master it (Bachelard 2004: 142), there is a chance that deeper insight into the publics' mental perception of the HGM would help both scientists and the public to build effective metaphors. This would also be of major importance in terms of the individual's decision-making process.

Nerlich has underlined the shift in the language spoken by scientists interested in either the Human Microbiome Project or in the Human Genome Project. The first group referring to "communities and ecologies" and the second to written information that one must decipher (Nerlich and Hellsten 2009). When analysing the press coverage and publications dedicated to the HGM, both in scientific journals and in the media, a non-exhaustive review demonstrates that metaphors today seem to be oriented towards an anthropomorphic view, as we will illustrate with the following examples (metaphorical terms quoted from the available literature are cited in italic).

The HGM as a landscape?

Considering, once again, that mental representation may rely on images, we suggest that before the "omic" techniques, the previous terms "gut microflora" and "gut barrier" suggested a kind of landscape. Indeed, the similarities between the HGM as a landscape and landscapes in general are intriguing. Dagognet in his article entitled “Death and resuscitation of landscape?" proposed that landscapes belong to the field of fighting energies as a kind of cemetery of signs, finally appealing to peace, harmony, moderation and rest, as the keeper of human traces (Dagognet et al. 1989). Likewise, landscapes appeal to the notions of heritage, as far as identity and belonging are concerned, and of longlasting development. Therefore, the landscape metaphor means a kind of preservation, which could foster reluctance to change. Yet, landscapes can be regarded from an individual or a collective point of view and it seems valuable to understand how they are perceived The notion of landscape appeals to power, justice and equity. Over time the landscape could be considered as a common good (open to everybody), as an heritage (everyone is responsible towards the future generations) and characterised by equity (Sgard 2010). Could not we apply this analysis to the field of HGM? Moreover, considering that changes in landscapes as well as modulations of the HGM are both related to human intervention, one must connect ethical and aesthetic concerns. Hence, the evocative images associated with landscapes and the gut microflora appeal to subjectivity in terms of perception, emotion and imagery. Both are finally rather hermetic to scientific knowledge, and seem to be cloaked under "mystery and 
circles of darkness"' (Dagognet et al. 1989: 33). But landscapes also appeal to the idea of a journey as a field to cross and discover. Once again, the HGM fits this metaphor if we consider the anatomy of the gut and the historical co-evolution of this microbial world with the human host (Zwart 2010). A recent paper dedicated to the expected use of faecal microbiota transplantation (FMT) has recently noted that "FMT has been used to treat an array of other gastrointestinal and non-gastrointestinal disorders, although experience in these other non-CDI diseases is in its infancy. [...] FMT is but the first step in this journey" (Brandt 2013: 177). We definitely agree that the current discovery of the actual symbiotic relationship between humankind and microbiota can be accepted as the very beginning of this special “journey". The central question should be to better define the ultimate goal of this unexpected “fantastic voyage'. We all know the expression "You are what you eat...'. The concept of HGM forces us to take another look.

The HGM as an organ?

As landscapes or the HGM appeal to personal subjectivity (the individual insight), there should not exist any conflict related to hierarchy of judgment as everyone associates a personal and relative importance to that ecosystem? And yet, things seem to be changing, as the HGM is sometimes referred to as a second stock of genes or as a second brain. In fact, as soon as the HGM is associated with vital functions, the issue of legitimacy returns and the HGM has to be examined, no longer as a landscape, but as an essential organ. Numerous studies have underlined the complex interactions between the HGM and our immune system (Kau et al. 2012). Beyond these captivating biological topics, these interactions also raise questions about the meaning of identity and otherness. Are we chimeras? Furthermore, to what extent should we consider the HGM as a human organ rather than a biological partner? What are our beliefs about symbiosis and mutualism? What does tolerance mean and what about the immunological rationale behind the self and non-self theory?

For instance, symbiotic gut bacteria have recently been elected as a matter of dispute to support or reject the immunological "danger theory" that was proposed twenty years ago (Pradeu and Cooper 2012). We suggest, once again, that this approach is not merely theoretical. If we consider the HGM as an organ, each modulation of its composition, following xenobiotic use (Maurice et al. 2013) or in the context of healthcare policy guidelines related to food intake, should be accepted as a "planned therapeutic manipulation" (Kelly 2013: 475) which seeks to improve Gut Health and to increase 
biovalue. Furthermore, we must take note that the HGM metaphor involves two special organs (the genes and the brain) in terms of autonomy, identity and ultimately in terms of how we define humankind.

The metaphor of the "gut microflora" or the way to grasp our internal symbiont as "our internal garden' might be understood as a call back to Eden and to the sacred function of gardens in ancient times, when they were supposed to connect Humankind with the Holy World. The inclination to see human beings as the centre of the world, as the expression of the Holy Will, has subsequently been shaken by three revolutions that are nothing less than "narcissistic insults": the Copernican revolution, confronting Mankind with the Universe, the Darwinian revolution, confronting Mankind with Evolution and the Psychoanalytical revolution, confronting Mankind with Mental Forces. There is a chance that the new paradigm of HGM might represent the fourth revolution, confronting Mankind with Microbes (Zwart 2012).

If humankind is no longer viewed as an embodied part of a Transcendental Goal deprived of any responsibility, but instead as an actor who is therefore shaping the Global Destiny, these revolutions expressed a heliocentric turn, which suggests that the Infinite in its various forms (the cosmos, mental forces, genome, and microbial world), could be compared to a value.

This perspective has dramatically influenced the inclination to see Nature and the Creation no longer as superior authorities but rather as things that Man could seize. This has led to the idea of progress and contributed to the notion of value. Finally, the information related to the advances in genomics applied to the field of HGM tends to demonstrate, at least at first glance, that this microbial world should never be considered as a landscape, but rather as an organ. And yet, as we will discuss below, the review of the available literature dedicated to the HGM research forces us to wonder if we should still regard the HGM as an organ.

The HGM as a portrait?

The available literature demonstrates that it is no longer a matter of considering the HGM even just as an organ. In fact today, although we do not precisely know the public's perception of the HGM, and considering that the information communicated through the scientific literature and the media is supplied mostly by scientists, it seems that the current scientific translation method aims at introducing the HGM as a being and no longer as a landscape or as an organ. For instance, the central objective of MetaHIT (Metagenomics of the Human Intestinal Tract, an international project financed by the European Commission) is to establish associations between the genes of the human intestinal microbiota and human health and disease, through an extensive reference catalogue of microbial genes present in 
the human intestine. As a result, if the HGM is considered as a being, it has been suggested that deciphering the HGM would be akin to undressing this bacterial world by the European MetaHIT Project.

In the same way, the usual perception of bacteria as enemies seems to evolve henceforth towards that of a neutral or even a beneficial partner that humans must help and preserve from dysbiosis (Blaser 2011). Obviously, there are numerous references related to conflicting relationships between humans and bacteria, but the current positive perception seems to balance the historically negative one, even though humans and the HGM are always trying to see who can get the upper hand. This evolution is translated in the print media as an ambiguous situation in which the HGM should be accepted either as a tool or an ally (a sort of interior partner that one should look after) or, to the contrary, as the master and lawmaker who controls human behaviour. As a result, today the HGM appears to be much more a partner to discover and to respect rather than a potentially disobedient community to conquer and enslave.

There also remain numerous references in the media to property, heritage and balance of power issues between the host and its bacteria. While it can be questioned whether the HGM should still be considered as an organ, metaphors teach us that Humankind no longer seems to have the control in this setting, since the HGM's genome acts silently and initiates the dialogue with the human brain. Thus the HGM seems to increase its control over what was once considered our free will, moving from a controlled status towards a commanding position. For instance, the HGM has even been suspected of playing with our mental state and even claiming an identity since it has been known as the gut signature. As one can see, current HGM metaphors suggest that our internal bacterial world can talk and sign, highlighting, through these two major human characteristics, its ability to behave like a human being. This assumption was clearly suggested in a recent medical article on the relationship between the HGM and colon cancer, which was entitled "HGM and Colorectal Cancer: Close Encounters of the Third Kind", in reference to the Steven Spielberg movie. The notion of signature conveys the idea of trace and fingerprint, then a relation with the concept of Time. Furthermore, the concept of the HGM signature and the ability of this ecosystem to dialogue with the human brain could also be accepted as the demonstration of a language, which, associated with the concept of heritage, could mean the foundations of a Culture. These reflections might suggest that depicting the HGM through a portrait would imply considering it as a human partner.

A compromise position based on the symbolic painting approach

[Tapez ici] 
We must keep in mind that metaphors usually challenge the familiar as well as the unfamiliar. Considering the close relationship between metaphors and symbols, on the one hand, and the etymological definition of symbols, which appeals to a kind of recognition and value, on the other hand, the current metaphor for portraying the HGM could also be understood as a representation of the human being himself as a new character with unusual features. In other words, to paraphrase Ricoeur's aphorism, portraying our gut microbiota could help us see oneself as another. Yet, a portrayal differs from resemblance since it is more than the sum of its various parts; thus, the portrait must attempt something more than just a resemblance of the features (Nancy 2000: 43). It implies the process of the observer's perception in terms of a kind of personal distance, which in turn would allow a personal emotional experience. From a phenomenological point of view, drawing a portrait still appeals to the notion of landscape whereas drawing an outline can be compared to a map with routes, slopes and climbs (Merleau-Ponty 1993: 292-293). Yet, these features considered as lines also help to circumscribe the figure, which is better defined and thus identified. In this way the portrait loses the landscape's mystery, as underscored by Dagognet. According to painting guidelines, the background of a portrait must be neutral, as a way to avoid competition and rivalry between the figure and other details. Consequently, the challenge for the painter is how to make the figure an actor. This seems a bit different with the HGM as it is usually described in the setting of exchanges and regulations with the human host, who could appear as an informative background. Nevertheless, we suggest that the portrait metaphor is still at work if we transpose the current HGM metaphors to the specific style of painting named Symbolism, which no longer refers to artistic creation (which is considered as the observer's insight claimed by the Naturalistic Painting style), but rather to the observer's soul and imagination. As a result, the painting metaphor for the HGM mixes the model itself (HGM), with its symbolic landscape (the exchanges with the human host); in other words, this HGM metaphor appeals by its format but it also directly addresses the importance of the observer's position in the analysis of HGM representation. Thus, the observer remains pivotal to sharing the respective weight of the notions of landscape and portrait related to his or her personal knowledge and understanding of the HGM. Evidence eventually shows that the HGM is no longer described today as just a landscape, an isolated organ or a mere portrait, but rather as a symbolic portrayal that blends the three metaphors. This shift even seems suggested in philosophical discourse since "genomics invites us to look upon ourselves as incubators, as it were, for symbiotic and cooperative microbes, rather than as vehicles for "selfish" genes" (Zwart 2010: 50). This kind of metaphor related to pregnancy refers to a new idea of humankind and of its functions, that combine the metaphors of portrait, organ and landscape. Evelyn Fox Keller has stressed that the criteria for assessing 
the truthvalue of words and images used in scientific language should be how effective they are (Fox Keller 1995). In fact it is accepted that metaphorical systems govern our lives, in an inconspicuous manner most of the time. The role of metaphors as a tool for apprehending the relation between language and reality in the fields of the gut and the body, as well as the risks of mistaken representations derived from cultural parameters have also been previously reported (Otis 2008). The most relevant metaphors for the field of the HGM remain to be determined, since we don't yet really know what the public understands when we refer to the HGM as our "second brain" or as a "second stock of genes". In the same way, one major finding of the MetaHIT program was to discover that, as seen with blood groups, the HGM might to be divided into three distinct enterotypes according to the dominant bacterium. Although subsequent studies have shown that things are probably more complex, and according to previous public misunderstanding, related to the hypothetical relationship between blood groups and human features, these results lead us to wonder how the concept of enterotypes impact our definition of humankind and how we can consider that our propensity to classify the bacteria composing microbiota implies that we must classify humans in turn. This reflection gives rise to the question of personalised medicine and addresses various issues at the intersection of health, diseases, therapeutics and wellbeing that will be discussed in the following section.

The HGM paradigm and forthcoming issues

The challenge of obesity

The role of the microbiota in most weight issues is now well-established so that the epidemic of obesity and its attendant chronic illnesses have been put forward as a priority in health policies (Lewis and Rosenthal 2011; Hunter and Reddy 2013). The evidence should imply advocating an optimal, scientifically-defined diet intended to maintain the ideal microbiota from a theoretical standpoint. The respective responsibilities of the patient and the physician in achieving this goal are yet to be debated (Steinbrook 2006). In any case, beyond the question of what should be considered as a normal weight, as questioned very recently (Flegal et al. 2013), we also have to wonder what could be an ideal HGM and how could we best design it, for instance, through diet adjustments. We must also ponder the meaning of a controlled and standardized diet. Indeed, what if each of us were to eat the same things to avoid pathologies? To what extent would we agree to relinquish our free-will and our autonomy as consumers? How can we prepare for a global, consumerdriven "age of nutrition"? There are as many answers as there are consumers, since the public's scientific knowledge is fed by scientists and [Tapez ici] 
physicians but also by the media and personal histories. As a result, historians are increasingly debating the role of medicine in defining health since the biological and social aspects are constantly interacting (Jones et al. 2012). A recent review has emphasized that "Many of the myths and presumptions about obesity reflect a failure to consider the diverse aspects of energy balance' (Casazza et al. 2013: 452). Thus, obesity is not merely a matter of metabolism even if the role of the balance between energy intake and expenditures cannot be underestimated. In fact, considering how long people who are overweight have been steered towards a slimming diet, one might imagine that they have gained a kind of expertise, at least as far as the nutritional qualities of foodstuffs are concerned. And yet, obesity has spread like an infectious agent across the planet as if no one were informed. Usually, weight reduction diets fail because they are associated with negative symbols: deprivation-frustration-transgression. From a metaphorical point of view, it is of interest that the gastric-ring, one of the most popular techniques used in bariatric surgery, can be compared with a kind of sacrament as if divine help were required. But the ring itself also means restriction and frustration, since its objective is to prevent obese people from feeding what they previously described as their internal abyss. Once again, the paradigm of the HGM could help the obese to look at nutritional advice in a new light, shifting from the landscape (the abyssal gut) to the portrayal (HGM as a personal actor). In such a way the HGM might henceforth no longer be considered as a superior and divine authority that deprives individuals from responsibility, but rather as a way to keep one's hand in diet adjustments. The task of subsequent behavioural techniques in nutrition programmes, integrating the concept of HGM could be to define if this ecosystem should be regarded by the patient as either an alter ego, a partner or a subcontractor. There is no doubt that behavioural therapy supported by a better understanding of digestion in the light of the HGM might play a key role in the management of obesity. Deciphering the HGM and its potential applications might not be that far from a "bio-psychoanalysis", which implies translational research at the intersection of "social, economic and environmental conditions that contribute to high rates of behaviour choices conducive to obesity" (Levy et al. 2007: 2318). The paradigm of the HGM obviously stands at the same pivotal position.

Antibiotics playing a new character part

The way consumers view their HGM might also influence the way how they modulate it. In other words, it could help consumers to take a stand on whether they manipulate the HGM as an organ, or instead consider it as a friendly partner that they must take care of. This obviously raises the concern of the acceptability of antibiotics and the impact these molecules have on the bacterial community. The current 
hygiene hypothesis suggests that the gut microbiota plays a key role in regulating the human body's immune responses. This hypothesis was first proposed in 1989 in the field of allergy. Since then, it has been brought to the fore to explain the role of the HGM in inflammatory bowel diseases and has also been proposed for extension to the fields of obesity and diabetes. This hypothesis states that the incidence of allergy depends of the rate of previous exposure to infections, but it has lacked scientific underpinnings until recently (Umetsu, 2012). This approach highlights another epistemological consideration faced by the HGM, which is related to the shifts in its composition caused by antibiotics, whether they have been misused or not. Antibiotic-related Clostridium difficile colitis is a typical example of an adverse effect but other, more unusual, associations arise, since even autism is mentioned (Finegold et al. 2002). On the opposite and anticipated positive side, antimicrobials have recently been invested with the mission of targeting obesity and metabolic conditions (Murphy et al. 2013). Basic research has also studied the role of microbiota in the field of depression (Foster 2013), whereas animal and clinical studies have suggested that it could also influence mate choice, kin recognition (Lize' and Lewis 2012), or host appetites (Norris et al. 2012). In contrast with the results of the previous studies, which stated that antibiotics would have only short-term consequences upon the HGM, it is now admitted that antibiotic overuse might provoke long-term physiological changes in the composition of the HGM (Pe'rez-Cobas et al. 2013) and consequently might alter the regulation between the gut and the brain. Thus, considering that the HGM could be deemed a "second brain", it can even be wondered to what extent it might control the human one. As the importance of mental disorders in the Global Agenda and of behavioural and dietary risk factors for noncommunicable diseases have been underscored very recently (Becker and Kleinman 2013; Ezzati and Riboli 2013), the misuse of antibiotics can no longer be assumed to have only bacteriological or short-term consequences (Blaser 2011). As we can see, the modulation of the HGM by antibiotics might definitely be of major importance in the individual's choice of behaviours with regards to foodintake, nutrition and perhaps even in the field of mental health. Indeed, some authors have recently shown the relationship between "cognitive and emotional processes"' and diet quality (Dinan and Cryan 2013: 1), suggesting that mental disorders should be included among noncommunicable diseases (Jacka et al. 2012) and might even be controlled through diet adjustment (Sanchez-Villegas and Martinez-Gonzalez 2013). A novel class of therapeutics called "psychobiotics", defined as " a live organism that, when ingested in adequate amounts, produces a health benefit in patients suffering from psychiatric illness"' (Dinan and Cryan 2013: 1), has even been proposed as a therapeutic alternative for mental disorders. But that's not all since the HGM is suspected to contribute to undernutrition (Gordon and Medzhitov 2013) and to irritable bowel disease. There are

[Tapez ici] 
also incredibly high expectations related to a novel use of antibiotics to address obesity and metabolic health that are increased tenfold by the fact that these molecules might also be of great interest in the management of malnutrition and functional digestive disorders. This has been experimented very recently with the use of antibiotics as a nutritional therapy for severe acute malnutrition (Trehan et al. 2013). We can thus observe an unbelievable and paradoxical situation in which HGM modulation would be used as a tool to address both the burden of obesity-related illnesses and the issue of malnutrition. All of these results highlight the increasing scope of therapeutic modulations of the HGM for personalised medicine, and therefore the central place of the consumer's position especially with regards to nutrition and antimicrobial agents. What if the HGM should be considered, from now on, as a therapeutic target for antibiotics in the field of nutrition? This would be a major shift that would definitely need specific and uncommon communication geared towards citizens and practitioners since it would be contrary to their beliefs. Efforts have concentrated until now on controlling and optimising the use of antibiotics in order to kill bacteria and avoid bacterial resistance, although the challenge is still before us. In fact, we must remember that antibiotics have been overused in the past in veterinary medicine and for non-therapeutic goals, such as improving animal growth. For instance, a recent study on the prevalence of multidrug-resistant Staphylococcus aureus (one of the most common bacteria in human infectious diseases), in US meat and poultry has still stressed the link between the use of antibiotics in food animal production and the emergence of novel bacterial resistance, even against the last-line molecules (Waters et al. 2011). Beyond the increasing scope of HGM manipulation, one must also remember that novelty and hope are usually associated with the risk of misusing the available knowledge and its suggested applications. In this possibility, and from the metaphorical standpoint that we consider as our "Ariadne's thread" for the purpose of this article, antibiotics are still viewed as an assault against the HGM, even if their purpose has moved from killing to modulating the bacteria. Considering that the HGM is today presented as a vast community of friendly bacteria, it would be interesting to wonder how ethical the interference of friends could be viewed. There is some chance that informing consumers about antibiotics and the HGM would become much trickier. For instance, the public's knowledge about antibiotics and their effects has recently been assessed in Austria as part of the Eurobarometer 2010 report devoted to antimicrobial resistance. This study demonstrated that antibiotic resistance was often thought to be related to the human host instead of the bacteria themselves (Hoffmann and Maier 2013). Beyond this misunderstanding, and once again as a tool for establishing correlations with HGM metaphors, it should be of interest to analyse whether an expert's message to explain the human body's mechanism of resistance to bacteria could help to specify whether the public 
view of antibiotics and the HGM remains positive or negative. Bacterial resistance is one of the most formidable challenges in the field of infectious diseases and has led to the implementation of novel strategies focused on HGM modulation either as a consequence of antibiotic misuse or as a way to limit the duration of colonisation by multi-drug resistant organisms (Tosh and McDonald 2012). For instance, the scientific and the lay literature have highlighted the potential benefit of probiotics to restore the HGM in the event of aggression by antibiotics. Despite some promising results in specific cases, the evaluation of the efficacy and safety of probiotics in clinical trials has had several setbacks related to methodological concerns (Tamayo 2008). Furthermore, the complexity of the HGM is likely to preclude the effectiveness of this kind of therapeutic focused on single microorganisms. Thus, in a near future, if antibiotics were to be the main therapeutics proposed to treat noncommunicable diseases, malnutrition, irritable bowel diseases or mental disorders, the issue of bacterial resistance could reach unprecedented levels. In this event, ethical issues related to the balance between the collective risk caused by bacterial resistance and the individual benefit of what is currently considered to be an inappropriate use of antibiotics would obviously come to the fore.

What about the future of faecal transplantation?

Besides the concern of bacterial resistance related to the overuse of antibiotics and the lack of definite guidelines regarding the benefit of probiotics, FMT should be considered as an ecological alternative as it aims to restore a ruined HGM with a vast sample of microorganisms. In other words and conversely to probiotics, FMT appears to be an attractive method that is adapted to the complexity of the HGM as an ecosystem. FMT was first described in 1958 in cases of life-threatening Clostridium difficile infections. The application to the HGM in human health has underscored the potential role of FMT, far beyond the field of antibiotic-related colitis. Interestingly, the first of the three main reasons that have been given, very recently, as an explanation for why FMT "has not become routine therapy for Clostridium difficile infection during the past 50 years" is that "it is aesthetically unappealing" (Kelly 2013: 474). Isn't that in itself a good reason to more deeply explore the mental representation of the HGM?

We find again the notion of aesthetics that we first associated with the landscape metaphor. Couldn't we consider FMT as a kind of ecological intervention that aims at restoring a ruined landscape? Indeed, using FMT to shorten bacterial colonisation also evokes the notion of defence against a hostile situation, but it does not refer to specific bacterial species and instead embraces the gut bacteria community as a whole. Thus, FMT is a means to resuscitate the internal landscape, as discussed above. This ecological [Tapez ici] 
perspective is also demonstrated by the efforts that are now concentrated on understanding how FMT could modulate the cross-talk between the HGM and the host's immune system, without altering the composition of the microbiota. Indeed, current studies on FMT highlight, in the field of the HGM, the intriguing relationship between the structure and the function as it has previously been reported in other fields, for example in deciphering the world of proteins. This should help, first, to compare a community's composition with its function and, second, to better define diagnostic tests derived from the HGM that would probably be of most interest if they were to express the values of "resistance and resilience rather than by a single measurement of composition" (Lemon and Fischbach 2012: 6). Nevertheless, although FMT appeals to the metaphor of landscape and ecology, the term transplantation also tends to refer to the HGM as an organ. In such an event and considering the close interactions that exist between the HGM and the host of the transplantation recipient, we could imagine that FMT might cause specific symptoms such as the feeling of depersonalisation as it has already been reported after solid-organ transplantation (Baranyi et al. 2013). Beyond the issues related to a person's internal life, FMT also raises the challenge of biobanking the HGM samples, which is confronted by severe limitations, such as "repulsive esthetics and inherent risk of pathogen transmission" (Tosh and McDonald 2012: 711). Although “auto-banking"' has been proposed to avoid these limitations, one must fear that the therapeutic potential of the HGM would outpace auto-banking capacities. Consequently, the implementation of FMT is bound to face ethical, legal and sociological issues, juxtaposing information and consent, individual rights and public safety, financial challenges for donors, and the storage of samples through biobanks, as recently reviewed in the field of transfusion medicine (Sacchini et al. 2013). Interestingly, it has recently been reported that blood-associated myths are still at work, related to severe transfusion hazards such as transfusion-transmitted infections and immunological complications (Garraud and Lefre're 2013). From the perspective of the blood transfusion experience, we could imagine that distrusting FMT could belie similar reservations, while the estimated risks of both techniques seem currently low. Furthermore, according to the increasing significance of the HGM in human health and acknowledging our current limited understanding, one might guess that the range of FMT indications is likely to evolve too, far beyond the purposes that would have warranted the initial biobanking collections. Thus, among the usual ethical concerns related to biobanks, the meaning of informed consent could be specifically addressed since it would not automatically cover additional and uninformed research (Hansson 2009). Finally, there is some chance that the use FMT will need to be built on what is known in the field of microbiology as national biobanks in the field of genetic databases. The "scientific rationale for such large, population-based collections, 
is the complexity of genetic contribution to common diseases and of the gene-environment interactions" (Mitchell 2010: 2). These population biobanks, grounded on the modulation of human tissue fragments, have a significant economic aspect that should not be underestimated, at least with respect to biomedical applications. From this perspective, the use of FMT definitely appeals to the notion of biovalue and could be regarded as a "shift from the civil discourse of participation to the economic discourse of labor'' (Mitchell 2010: 13), which addresses several concerns about equity. As we can see, the meaning of faecal transplantation, which tends to be proposed as a safe and accepted treatment for Clostridium difficile colitis, will no longer be considered as just a simple therapeutic alternative in the near future (Kahn et al. 2012). It will also appeal to economic issues related to the concept of biovalue as well as to ethics and deontology, as suggested broadly by Kent: "What we see emerging in the 21 st century is a new kind of 'tissue economy' [...] where the commodification of human tissue is at the centre of therapies based on the procurement, processing, manipulation and regeneration of tissues and cells" (Kent 2012: 1). Thus, some authors have alerted the medical community about (1) the probable and current limitations of HGM modulation due to the incomplete repertoire available for this complex ecosystem (Lagier et al. 2012), and (2) the need for a special reflection dedicated to the actual benefitrisk ratio for HGM modulation, as suggested with the use of faecal transplantation therapy (El-Matary et al. 2012).

We are forced to conclude that scientific enthusiasm sometimes prevails over wisdom, and yet, taking an epistemological approach should definitely not be regarded as irrelevant if we consider (1) that studies show the increasing role of the HGM in many metabolisms and clinical conditions, most of them involved in what are known as noncommunicable diseases (Tremaroli and Ba"ckhed 2012), (2) that the HGM evolves with the nature of our diet (Claesson et al. 2012), and (3) that the microbiota of a newborn depends first on its mother's diet (Saavedra and Dattilo 2012). Our responsibility for the health of future generations is no longer ignored, and even the term "noncommunicable diseases" could be revised. But our personal responsibility can be assumed at a more modest level if we consider that FMT and antibiotics would aim at the same goals in terms of prevention and treatment of noncommunicable diseases. In fact, since FMT remains, at the least, far less appealing than antibiotic pills, there is a chance that in the event of a decision-making process regarding the two options, a patient or a consumer would choose the later, regardless of antibiotic resistance. On the other hand, according to Scanlon's contractualism applied to the use of antibiotics, Millar has proposed that "the level of risk at which we consider the use of an antibiotic to be justified should be above a level which approximates to the levels of risk which we tolerate in our daily lives"' (Millar 2012: 467). As cooking and diet adjustments stand 
at the intersection of daily life risks and of risk factors associated with noncommunicable diseases, one can anticipate that a "Scanlon's approach" to the use of antibiotics would preclude their implementation in such a case and would accept diet as the best option. This raises the question of the level of constraint that health policies might exert on the use and consumption of antibiotics. As a result, the burgeoning realm of the HGM's applications in human health and the concerns related to antibiotic misuse as well as to FMT issues, all highlight the potential burden of diet adjustments. They also point to the importance of shifts in the consumer's attitude specifically in the area of nutrition programmes and, more broadly, as a way to improve their wellbeing and overall health, as we will discuss below.

The scientists, the food industry and the public: from wellbeing to self-enhancement

Today, consumers must manage with various sources of information related to food intake, and translate that knowledge into concrete dietary habits that inform practices such as shopping, cooking and eating (Blue 2010). Our reflection heretofore is based on the following observations: (1) the observed duplicity of the food industry in addressing social, ethical and Global Health concerns related to noncommunicable diseases and food intake has been addressed recently in some journal's series (Stuckler and Nestle 2012; Robbins and Nestle 2012); (2) the fallback option for the public to turn to the media as the only way to get scientific information might be the result of scientists' lack of engagement in knowledge translation beyond a purely scientific audience (Suleski and Ibaraki 2010); (3) the key role of general practitioners and family doctors reported in the field of antibiotics in representing the behaviour of a trustworthy person (Hoffmann and Maier 2013) doesn't guarantee that they would be persuasive enough to modulate the HGM in healthy patients, for instance, as a preventive programme, as it has been reported previously in the case of Clostridium difficile colitis (Zipursky et al. 2012). Furthermore, one can wonder what would be the nature of the traditional "expert medical advice" when the physician is himself obviously a consumer in the field of the HGM. This also questions how accurate the translation of knowledge by the scientists and the food industry can be, as a way to improve the HGM through nutrition programmes or diet adjustment. Yet, scientific research most of the time depends on private funding, and however scientists communicate with Society, it always comes down to a matter of trust, especially in the field of biomedicine. The goal of scientific communication, at least in the field of nutrition and diet, can no longer be accepted to compensate the so-called public's deficit in knowledge.

We see that a two-way dialogue between scientists and consumers devoted to the understanding of HGM research rests on individual experiences related to the personal meaning of Gut Health. Thus, it 
appeals to the notion of wellbeing, which is most of the time evaluated in six different areas: occupational, emotional, spiritual, intellectual, social and of course physical (McMahon et al. 2010). Yet, the understanding and evaluation of wellbeing may evolve according to which discipline is scrutinised, meaning that the importance of each specific criterion is likely to differ, resulting in confusing messages. Since individual food choice and diet policies obviously depend on these aspects, the HGM paradigm forces us to evaluate how the public hitself considers wellbeing in the light of Gut Health and how far diet may express social determinants. This gives rise to wondering whether we move predictably towards a standardised diet or to what extent social memberships would assimilate forthcoming nutritional guidelines. As such, this could be a reflection related to the meaning Society attributes to the representation of the individual body. This leads to the question of beauty and aestheticism, then to the confrontation of the visible and the invisible, since the HGM paradigm sheds light on our internal and invisibles microbes that were associated until recently with negative features such as risk, dirtiness, nuisance, and diseases. One can also presume that modulating the HGM as a way to avoid human pathology and improve Global Health would lead to the notion of health enhancement. This could be considered to be "moderate eugenics", as recently discussed in the Journal (Selgelid and Enhancement 2013). This also raises the matter of a "self-reflected transhumanism” (Tennison 2012), focused on the assumption that the human body itself, through the modulation of the HGM, has continuously evolved, from the very beginning, to adapt its behaviour to the environment. The point is that this has always been unwittingly done until now, since the determinants of human food choice were not really analysed before. The great challenge faced by consumers from now on, is to rapidly gain the ability to form an opinion on fields that were heretofore out of their range. Moreover, considering that the HGM is a major regulator of the brain-gut axis, we could imagine that modulating the HGM through driven shifts of food intake could ultimately lead humankind to reach a kind of moral enhancement which is steadily discussed (Persson 2013). Consequently, the HGM paradigm induces ethical questions far beyond the issues usually associated with the matters of consent or biobanking. As it would involve the consumers' diet and the drug industry, the HGM paradigm also raises ethical issues in terms of justice and equity if it is to benefit the whole of Society, regardless of individuals' incomes or social positions. These concerns go far beyond the goals of the topic but they should obviously be studied further specifically through the scope of political philosophy.

[Tapez ici] 


\section{Perspectives}

We have considered that the available scientific and lay literature related to the concept of the HGM, especially focusing on therapeutic consequences through its potential modulation in the context of human health and diseases, provides solid reasons to more deeply explore this concept before going further with more formal applications. We have sought to demonstrate that the meaning of the HGM, which could be accepted as a potential new paradigm in biology and in human healthcare, could be approached with substantial improvement through a dedicated analysis of the public understanding of this field, which has never been reported previously, beyond the realm of human pathology. As a result, the next step of our reflection will be the implementation of more structured sociological studies, as a way to inform professional circles on the public's beliefs and expectations, if any, in order to build consensual and effective policies in the field of nutrition.

The HGM paradigm is an amazing and evolving challenge. We are aware that our work is nonexhaustive, since other issues will probably arise in the near future, as a result of advances in the "omic" techniques applied to the HGM. Yet, we conclude our reflection with the question of self-enhancement, as we hope to demonstrate that considering the HGM from the standpoint of metaphor is not merely academic. We suggest at least two approaches to further studies, as a second and more formal step of our work.

First, exploring HGM metaphors leads to a consideration of societal and public health issues, which are essential to meet the Global Health challenge. Evidence shows that metaphors seem to be unavoidable as a tool for a mutual dialogue, provided each partner expresses a real awareness of the person who is speaking. This implies taking into consideration social and cultural backgrounds and assimilating the theoretical benefits of HGM modulations within personal contexts. Consequently, according to the results of the presented work that emphasise the potential diversity of HGM perceptions among the public, we propose to create formal meetings, as a means to implement further sociological studies. They will be dedicated to the mental perception of Gut Health in the era of the HGM and target specific and well-identified populations, such as academic biologists, food industry members, physicians, and lay consumers.

Second, as the potential medical applications of HGM research affect diet and noncommunicable diseases, antibiotics and bacterial resistance or even mental disorders and human behaviour, the HGM paradigm forces us to think about it in terms of autonomy, liberty, equity and self-determination. Bringing the HGM to light also drives each consumer to think deeply about how self-consent should be considered, which depends firstly on the way the HGM is pictured by the individual. These 
considerations appeal to philosophical debate with competing political philosophies such as utilitarians, egalitarians and libertarians. This obviously means that the HGM paradigm is closely linked to healthcare policies and, as a result, to politics as a whole. Therefore it is our goal to convince politicians that the HGM must exist as a specific consideration in a manifesto. For instance, attention has been focused on French Gastronomy in terms of the high quality of cooking but also in terms of the benefits of sharing meals. It is our hope to integrate the HGM paradigm as a key factor of diet in these political circles, which should not be insensitive to the concept of biovalue.

We assert that the HGM could be a point of encounter between medico-scientific advances, the socalled "bioeconomy" and the crucial philosophical consideration related to the evolving concept of Man. The fascinating world of the HGM underscores the benefits of diversity in terms of efficiency and adaptability. The translational approach, combining social and fundamental sciences, aims at the same goals. This issue is at our doorstep. Won't we regret it if we continue to ignore it?

Acknowledgments The authors are grateful to Koren WolmanTardy and Victoria Paykar for their helpful assistance. The authors also thank the anonymous reviewers for the journal for their shrewd and constructive comments on the paper.

\section{References}

Asch, D.A., and K.G. Volpp. 2012. What business are we in? The emergence of health as the business of health care. New England Journal of Medicine 367: 888-889.

Atun, R., F.M. Knaul, Y. Akachi, and J. Frenk. 2012. Innovative financing for health: What is truly innovative ? Lancet 380: 2044-2049.

Bachelard, G. 2004. La poe'tique de l'espace, 215. Paris: Quadrige/ PUF.

Bachelard, G. 1967. La formation de l'esprit scientifique. Contribution a' une psychanalyse de la connaissance objective. Paris: Librairie philosophique J. VRIN, $5^{\mathrm{e}} \mathrm{e}^{\prime}$ dition. Collection : Bibliothe 'que des textes philosophiques, $257 \mathrm{p}$.

Baker, S.R., and L. Partyka. 2012. Relative importance of metaphor in radiology versus other medical specialties. Radiographics 32: 235-240.

Bapteste, E., and J. Dupre'. 2013. Towards a processual microbial ontology. Biology and Philosophy 28: $379-404$.

[Tapez ici] 
Baranyi, A., T. Krauseneck, and H.-B. Rothenha"usler. 2013. Overall mental distress and health-related quality of life after solid-organ transplantation: Results from a retrospective follow-up study. Health and Quality of Life Outcomes 11: 15. doi:10.1186/14777525-11-15.

Becker, A.E., and A. Kleinman. 2013. Mental health and the global agenda. New England Journal of Medicine 369: 66-73.

Bischoff, S.C. 2011. Gut health: A new objective in medicine? BMC Medicine 9: 24. doi:10.1186/17417015-9-24.

Blaser, M. 2011. Stop the killing of the beneficial bacteria. Science 476: 393-394.

Blue, G. 2010. Food, publics, science. Public Understanding of Science 19: 147-154.

Brandt, L.J. 2013. American journal of gastroenterology lecture: Intestinal microbiota and the role of fecal microbiota transplant (FMT) in treatment of C. difficile infection. American Journal of Gastroenterology 108: 177-185.

Brinich, M.A., M.B. Mercer, and R.R. Sharp. 2013. An analysis of online messages about probiotics. BMC Gastroenterology 13: 5. doi:10.1186/1471-230X-13-5.

Casazza, K., K.R. Fontaine, A. Astrup, et al. 2013. Myths, presumptions, and facts about obesity. New England Journal of Medicine 368: 446-454.

Claesson, M.J., I.B. Jefferty, S. Conde, et al. 2012. Gut microbiota composition correlates with diet and health in the elderly. Nature 488: 178-184.

Clayton, E.W. 2003. Ethical, legal, and social implications of genomic medicine. New England Journal of Medicine 349: 562-569.

Cummings, J.H., J.M. Antoine, F. Azpiroz, et al. 2004. PASSCLAIM: Gut Health and immunity. European Journal of Nutrition 43(Suppl 2): II118-II173.

Dagognet, F., F. Guery, and O. Marcel. 1989. “'Mort et re'surrection du paysage ?', in Mort du paysage ?. Champ vallon: Philosophie et esthe'tique du paysage. $240 \mathrm{p}$.

Dinan, T.G., Stanton, C., and J.F. Cryan. 2013. Psychobiotics: A novel class of psychotropic. Biological Psychiatry. doi: 10.1016/ j.biopsych.2013.05.001.

Eden, S. 2011. Food labels as boundary objects: How consumers make sense of organic and functional foods. Public Understanding of Science 20: 179-194.

El-Matary, W., R. Simpson, and N. Rickett-Burns. 2012. Fecal microbiota transplantation: Are we opening a can of worms? Gastroenterology 143: e19. doi:10.1053/j.gastro.2012.04.055.

Ezzati, M., and E. Riboli. 2013. Behavioral and dietary risk factors for noncommunicable diseases. New England Journal of Medicine 369: 954-964. 
Fineberg, H.V., and D.J. Hunter. 2013. A global view of health: An unfolding series. New England Journal of Medicine 368: 78-79.

Finegold, S.M., D. Molitoris, Y. Song, et al. 2002. Gastrointestinal microflora studies in late-onset autism. Clinical Infectious Diseases 35(Suppl 1): S6-S16.

Flegal, K.M., B.K. Kit, H. Orpana, and B.I. Graubard. 2013. Association of all-cause mortality with overweight and obesity using standard body mass index categories: A systematic review and metaanalysis. Journal of the American Medical Association 309: 71-82.

Foster, J.A., and K.A. McVey Neufeld. 2013. Gut-brain axis: How the microbiome influence anxiety and depression. Trends in Neuroscience. doi:10.1016/j.tins.2013.01.005.

Fox Keller, E. 1995. Refiguring life: Metaphors of twentieth-century biology. Columbia University Press, $134 \mathrm{p}$.

Garraud, O., and J-.J. Lefre're. 2013. Are there still myths in -or associated with- transfusion ? Blood Transfusion 11: 148-150.

Goffette, J., and J. Simon. 2012. "The internal environment: Claude Bernard's concept and its representation in Fantastic Voyage (R. Fleisher)', pp. 187-205, In: Landers Matthew Munoz Brian (ed.): Anatomy and the organization of knowledge, 1500-1850, London, Pickering Chatto.

Gordon, J.I., Dewey, K., Mills, D.A., and R.M. Medzhitov. 2013. The human gut microbiota and undernutrition. Science Translational Medicine 4:137ps12. doi: 10.1126/scitranslmed.3004347.

Grad, F.P. 2002. The preamble of the Constitution of the World Health Organization. Bulletin of the World Health Organization 80: 981-984.

Greenhalgh, T., and S. Wieringa. 2011. Is it time to drop the "knowledge translation" metaphor? A critical literature review. Journal of the Royal Society of Medicine 104: 501-509.

Hansson, M.G. 2009. Ethics and biobanks. British Journal of Cancer 100: 8-12.

Hawkes, C., and K. Buse. 2011. Public health sector and food industry interaction: It's time to clarify the term "partnership" and be honest about underlying interests. European Journal of Public Health 21: 400-403.

Hawkins, A.K., and K.C. O’Doherty. 2011. "Who owns your poop ?': Insights regarding the intersection of human microbiome research and the ELSI aspects of biobanking and related studies. BMC Medical Genomics 4: 72. doi:10.1186/1755-8794-4-72.

Hoffmann, C., Risti, R., Heschi, L., Stelzer, D., and M. Maier. 2013. Antibiotics and their effects: What do patients know and what is their source of information? The European Journal of Public Aug 19.

[Tapez ici] 
Hudson, K.L. 2011. Genomics, health care, and society. New England Journal of Medicine 365: 10331041.

Hunter, D.J., and S. Reddy. 2013. Noncommunicable diseases. New England Journal of Medicine 369: $1336-1343$.

Jacka, F.N., A. Mykletun, and M. Berk. 2012. Moving towards a population health approach to the primary prevention of common mental disorders. BMC Medicine 10: 149. doi:10. 1186/1741-701510-149.

Janes, C.R., K.K. Corbett, J.H. Jones, and J. Trostle. 2012. Emerging infectious diseases: The role of social sciences. Lancet 380: 884-886.

Jones, D.S., S.H. Podolsky, and J.A. Greene. 2012. The burden of disease and the changing task of medicine. New England Journal of Medicine 366: 2333-2338.

Kahn, S.A., R. Gorawara-Bhat, and D.T. Rubin. 2012. Fecal bacteriotherapy for ulcerative colitis: Patients are ready, are we? Inflammatory Bowel Diseases 18: 676-684.

Kau, A.L., P.P. Ahern, N.W. Griffin, A.L. Goodman, and J.L. Gordon. 2012. Human nutrition, the gut microbiome, and immune system: Envisioning the future. Nature 474: 327-336.

Kelly, C.P. 2013. Fecal microbiota transplantation - An old therapy comes of age. New England Journal of Medicine 368: 474-475.

Kent, J., A. Faulkner, I. Geesink, and D. Fitzpatrick. 2006. Culturing cells, reproducing and regulating the self. Body \& Society 12: 1-23.

Klingler, C. 2009. Notre seconde re'serve de ge`nes. La Recherche 430: 31.

Lagier, J.C., M. Million, P. Hugon, F. Armougom, and D. Raoult. 2012. Human gut microbiota: Repertoire and variations. Frontiers in Cellular and Infection Microbiology 2: 136. doi:10.3389/ fcimb.2012.00136.

Lemon, K.P., Armitage, G.C., Relman, D.A., and M.A. Fischbach. 2012. Microbiota-targeted therapies: An ecological perspective. Science Translational Medicine 4: 137vr5.

Levy, R.L., E.A. Finch, M.D. Crowell, N.J. Talley, and R.W. Jeffery. 2007. Behavioral intervention for the treatment of obesity and effectiveness data. American Journal of Gastroenterology 102: 23142321.

Lewis, K.H., and M.B. Rosenthal. 2011. Individual responsibility or a policy solution - Cap and trade for the U.S. diet? New England Journal of Medicine 365: 1561-1563.

Lize', A., McKay, R., and Z. Lewis. 2012. Gut microbiota and kin recognition. Trends in Ecology and Evolution http://dx.doi.org/ 10.1016/j.tree.2012.10.013. 
Maurice, C.F., H.J. Haiser, and P.J. Turnbaugh. 2013. Xenobiotics shape the physiology and gene expression of the active human gut microbiome. Cell 152: 39-50.

McDonald, D., Y. Vazquez-Baeza, W.A. Walters, J.G. Caporaso, and R. Knight. 2013. From molecules to dynamic biological communities. Biology and Philosophy 28: 241-259.

McMahon, A., P. Williams, and L.C. Tapsell. 2010. Reviewing the meaning of wellbeing and wellness and their implications for food choice. Perspectives in Public Health 130: 282-286.

Mercer, M.B., M.A. Brinich, G. Geller, et al. 2012. How patients view probiotics: Findings from a multicentre study of patients with inflammatory bowel disease and irritable bowel syndrome. Journal of Clinical Gastroenterology 46: 138-144.

Merleau-Ponty, M. 1993. Phe'nome'nologie de la perception [1945]. Paris: Gallimard. 531 p.

Millar, M. 2012. Constraining the use of antibiotics: Applying Scanlon's contractualism. Journal of Medical Ethics 38: 465-469.

Mitchell, R. 2010. National biobanks: Clinical labor, risk production and the creation of biovalue. Science, Technology and Human Values 35: 330-355. doi:10.1177/0162243909340267.

Mordini, E. 2007. Technology and fear: Is wonder the key? Trends in Biotechnology 25: 544-546.

Moschen, A.R., V. Wieser, and H. Tilg. 2012. Dietary factors: Major regulators of the gut microbiota. Gut and Liver 6: 411-416.

Mouton, L. 2010. The contribution of philosophy to immunology. Presse Me'dicale 39: 745-746.

Murphy, E.F., P.D. Cotter, A. Hogan, et al. 2013. Divergent metabolic outcomes arising from targeted manipulation of the gut microbiota in diet-induced obesity. Gut 62: 220-226.

Nancy, J.L. 2000. Le regard du portrait. Paris: Galile'e. 90 p.

Nerlich, B., R. Dingwall, and D.D. Clarke. 2002. The book of life: How the human genome project was revealed to the public. Health: An interdisciplinary journal for the social study of health, illness and medicine 6: 445-469.

Nerlich, B., and I. Hellsten. 2004. Genomics: Shifts in metaphorical landscape between 2000 and 2003. New Genetics and Society 23: 255-268.

Nerlich, B., and I. Hellsten. 2009. Beyond the human genome: Microbes, metaphors and what it means to be human in an interconnected post-genomic world. New Genetics and Society 28: 19-36.

Norris, V., F. Molina, and A.T. Gewirtz. 2012. Hypothesis: Bacteria control host appetites. Journal of Bacteriology 195: 411-416.

O’Malley, M.A., and J. Dupre'. 2007. Size doesn't matter: Towards a more inclusive philosophy of biology. Biology and Philosophy 22: 155-191.

[Tapez ici] 
O’Malley, M.A. 2013. Philosophy and the microbe: A balancing act. Biology and Philosophy 28: 153159.

Otis, L. 2008. Going with your gut: Some thoughts on language and the body. Lancet 372: 798-799.

Pe'rez-Cobas, A.E., M.J. Gosalbes, A. Friedrichs, et al. 2013. Gut microbiota disturbance during antibiotic therapy: A multi-omic approach. Gut 62: 1591-1601.

Persson, I. 2013. Could it be permissible to prevent the existence of morally enhanced people? Journal of Medical Ethics 38: 692-693.

Petrof, E.O., E.C. Claud, G.B. Gloor, and E. Allen-Vercoe. 2013. Microbial ecosystems therapeutics: A new paradigm in medicine? Beneficial Microbes 4: 53-65.

Podolsky, S.H. 2012. Metchnikoff and the microbiome. Lancet 380: 1810-1811.

Pradeu, T., and E.L. Cooper. 2012. The danger theory: 20 years later. Frontiers in Immunology 3: doi: 10.3389/fimmu.2012.00287.

Robbins, A., and M. Nestle. 2012. Obesity as collateral damage: A call for papers on the obesity epidemic. Journal of Public Health Policy 32: 143-145.

Saavedra, J.M., and A.M. Dattilo. 2012. Early development of intestinal microbiota: Implications for future health. Gastroenterology Clinics of North America 41: 717-731.

Sacchini, D., G.M. Liumbruno, G. Bruno, et al. 2013. Ethical and deontological issues in transfusion medicine. Blood Transfusion 11: 14-25.

Sanchez-Villegas, A., and M.A. Martinez-Gonzalez. 2013. Diet, a new target to prevent depression ? BMC Medicine 11: 3. doi:10. 1186/1741-7015-11-3.

Selgelid, M.J. 2013. Moderate eugenics and human enhancement. Medicine Health Care and Philosophy Jun 1 .

Sgard, A. 2010. '“Une e'thique du paysage est-elle souhaitable ?', VertigO: La revue e'lectronique en sciences de l'environnement [Online], Volume 10 Nume'ro 1 I avril 2010. URL : http:// vertigo.revues.org/9472; doi : 10.4000/vertigo.9472.

Slashinski, M.J., S.A. McCurdy, L.S. Achenbaum, S.N. Whitney, and

A.L. McGuire. 2012. "'Snake-oil', “quack medicine”, and "industrially cultured organisms": Biovalue and the commercialization of human microbiome research. BMC Medical Ethics 13: 28. doi:10.1186/1472-6939-13-28.

Steinbrook, R. 2006. Imposing personal responsibility for health. New England Journal of Medicine 355: $753-756$. 
Stuckler, D., and M. Nestle. 2012. Big food, food systems, and Global Health. PLoS Medicine 9(6): e1001242. doi:10.1371/journal. pmed.1001242.

Suleski, J., and M. Ibaraki. 2010. Scientists are talking, but mostly to each other: A quantitative analysis of research represented in mass media. Public Understanding of Science 19: 115-125.

Svalastog, A.L. 2010. Gene myths in public perceptions. Public Understanding of Science 21: 478-494.

Tamayo, C. 2008. Clinical research on probiotics: The interface between science and regulation. Clinical Infectious Diseases 46(Suppl 2): S101-S103.

Tennison, M.N. 2012. Moral transhumanism: The next step. Journal of Medicine and Philosophy 37: 405-416.

Tosh, P.K., and L.C. McDonald. 2012. Infection control in the multidrug-resistant era: Tending the human microbiome. Clinical Infectious Diseases 54: 707-713.

Trehan, I., H.S. Goldbach, L.N. LaGrone, et al. 2013. Antibiotics as part of the management of severe acute malnutrition. New England Journal of Medicine 368: 425-435.

Tremaroli, V., and F. Ba“ckhed. 2012. Functional interactions between the gut microbiota and host metabolism. Nature 489: 242-249.

Triggle, D.J. 2012. Nous sommes tous des bacte'ries: Implications for medicine, pharmacology and public health. Biochemical Pharmacology 84: 1543-1550.

Umetsu, D.T. 2012. Early exposure to germs and the Hygiene Hypothesis. Cell Research 22: 12101211

[Tapez ici] 


\section{View publication stats}

van de Weele, C. 2008. How to do with metaphor? Introduction to the issue. Configurations 16: 1-10.

Waldby, C. 2002. Stem cells, tissue cultures and the production of biovalue. Health: An Interdisciplinary Journal for the Social Study of Health. Illness and Medicine 6: 305-323.

Waters, A.E., T. Contente-Cuomo, J. Buchhagen, et al. 2011. Multidrug-Resistant Staphylococcus aureus in US Meat and Poultry. Clinical Infectious Diseases 52: 1227-1230.

Zarraonaindia, I., D.P. Smith, and J.A. Gilbert. 2013. Beyond the genome: Community-level analysis of the microbial world. Biology and Philosophy 28: 261-282.

Zimmer, C. 2011. Our microbiomes, ourselves. Review December: The New York times - Sunday. 3.

Zinken, J., Hellsten, I., and B. Nerlich. 2008. Discourse metaphors. In R. Dirven, R. Franck, T. Ziemke, and J. Zlatev (Eds), Body, language, and mind. Volume 2: Social situatedness. Berlin: Mouton de Gruyter, $441 \mathrm{p}$.

Zipursky, J.S., T.I. Sidorsky, C.A. Freedman, M.N. Sidorsky, and K.B. Kirkland. 2012. Patient attitudes towards the use of fecal microbiota transplantation in the treatment of recurrent Clostridium difficile infection. Clinical Infectious Diseases 55: 1652-1658.

Zwart, H. 2009. From utopia to science: Challenges of personalized genomics information for health management and health enhancement. Medicine Studies 1: 155-166.

Zwart, H. 2010. Towards an eco-centric view of human existence: Implications of genomics for the environmental zone. Genomics, Society and Policy 6: 40-55.

Zwart, H. 2012. On decoding and rewriting genomes: A psychoanalytical reading of a scientific revolution. Medicine, Health Care and Philosophy 15: 337-346. 